\title{
EdD Program Reform and Signature Pedagogies for Activism
}

\author{
Yasha Jones Becton \\ University of South Carolina \\ YYJones@mailbox.sc.edu \\ Rhonda Baynes Jeffries
University of South Carolina \\ rjeffries@sc.edu
}

\begin{abstract}
In the Carnegie Foundation's studies of preparations for the professions, we have gone into considerable depth to understand the critical role of signature pedagogies in shaping the character of future practice and in symbolizing the values and hopes of the profession. ... Above all we have found it fruitful to observe closely the pedagogies of the professions in [action]. (Shulman, 2005, p. 53)
\end{abstract}

The Carnegie Project on the Education Doctorate (CPED) consortium of over 100 colleges and schools of education across the U.S. and Canada, regularly and purposefully convenes to collectively explore the effectiveness of the education doctorate to support the professional goals and objectives of educational leaders and administrators. These collaborative sessions facilitate the critique of emerging and premiere Doctor of Education (EdD) programs, and foster the negotiation of educational practice and innovative design across the professional practice of teaching and learning. As professional development opportunities, CPED convenings are fertile ground for the growth of resources from member programs' contributions to the design and redesign of EdD programs. With attention to continued improvement -- theoretical knowledge that guides the curriculum and instruction of schools and contributes to the policy that governs schools -- members from across the consortium are committed to shaping educational outcomes that support practitioners ability to optimally serve learners.

The CPED Framework@ in Action is one among many consortium benefits that drives the goal of program redesign, and the signature pedagogy design concept is one element of the CPED Framework@ in Action that has manifested in EdD programs in a variety of ways. Olson and Clark's (2009) response to the education doctorate debate that proliferated in the mid-2000s described the use of leader-scholar communities as a signature pedagogy to support the goals of professional educators based on a model utilized at Arizona State University. The adaptation of signature pedagogies from related disciplines was suggested as a method for familiarizing students with the existing knowledge base in the field of education as well as orienting them to the cultural norms and disciplinary identities of education scholars (Golde, 2007). Action research as a methodological design or equity and social justice as a theoretical design have been noted as signature pedagogies that effectively ground the doctoral studies of education practitioners, and create a seamless segue from doctoral candidacy back into the field of practice (Buss, Zambo, Zambo, Perry, \& Williams, 2015). Online environments are increasingly favored as in-service education professionals seek high quality doctoral programs that accommodate their demanding schedules. An innovative signature pedagogy in use at East Carolina University applied digital storytelling and Flip Grid, a

New articles in this journal are licensed under a Creative Commons Attribution 4.0 United States License. Program and is cosponsored by the University of Pittsburgh Press. video-based online discussion forum, in their online EdD to highlight the critical nature of maintaining strong relationships that support critical dialogue in this unique learning environment (Militello, Tredway, \& Jones, 2019).

This special issue of Impacting Education: Journal for Transforming Professional Practice, is entitled, "Activating Activism: Promoting Activism within EdD Programs". Born from the 2019 CPED Convening held at the University of South Carolina, and focusing on Interaction and Activism in the Education Doctorate, this issue aimed to expand the conversation on social justice in education and create lasting impact through activism. As Shulman (2005) suggested, the contributions to this special issue examine activism as a signature pedagogy in action, and challenge our prevailing conceptions of what activism is and how implementation of this signature pedagogy might be most meaningful. We, Becton and Jeffries, along with our colleagues, Bogiages, Currin, D'Amico, Lilly, and Tamim, surveyed the 2019 October Convening participants from more than 65 represented CPED memberships in an effort to build upon the existing structured pedagogies that guide both new and existing EdD programs within the consortium. In An Emerging Framework for the Ed.D. Activist, outcomes from this work highlighted two probable sketches of what an EdD activist looks like, and how programs might structure their curricula to support the development and sustainment of EdD activists in the professional setting.

Additional articles in this special issue represent diverse ideologies from across the U.S. regarding ways to structure the theoretical underpinnings and practical application of activism in EdD programs. In SMACKtivism: A Program Redesign So Good, You Won't Know What Hit You, Noel, Gorlewski, and Kearney described the attributes of their newly designed EdD program focusing on learning and teaching in social contexts. The authors built the potential program with the intention of compelling their candidates to embrace transformative and justice-oriented fundamentals that will empower them to improve their educational spaces via activism throughout their careers. The power of experiential learning and relationships is paramount in Opening Up to Hard History: Activating Anti-Racism in an Immersive EdD Cohort Experience at 
Heritage Sites in Montgomery, Alabama by Coble, Mason, Overholser, and Gwaltney. This EdD program in Heritage Leadership for Sustainability, Social Justice, and Participatory Culture at the University of Missouri-St. Louis helps students through curricular, conversational, and collaborative inquiry to deepen their awareness of discrimination and injustice. Students learn specific skills that are transferrable into educational settings and support the direct work of activism. In Launching an EdD in Community College Leadership Program with Activism in Mind, another emerging program design is discussed and shared as a model for program development and reform. Harrington and Melendez covered aspects of program planning in this piece including design and implementation, marketing and recruitment, diversity of cohort building, and orientation to the EdD experience as well as the fundamental aspect of social justice and equity as a framework for program design. Critical implications focus on the importance of equity as the thread that holds the entire program together and instills the essential nature of the social justice component to activist work. Hesbol, Bartee, Sparkman and Amiri examined the impact of activism in rural environments in Activism in Practice: The Influence of a Rural School Leader's Beliefs and Practices in Disrupting Historical Patterns of Underachievement in Traditionally Marginalized Students and noted the mutual inclusivity of high achievement at high poverty rural schools when school leaders utilize principles of activism. This study highlights the role of education doctorate programs to influence their students to function as researchers, to influence policy, and to acknowledge the nuanced work of effective educational activists. Finally, in Taking a Stance: Teacher Researchers' Historical and Political Positioning, Currin challenged the traditional grassroots model of activism and suggested that more conservative methods attempting to reform from within the system might yield more impactful results as opposed to the outcomes that demonstrative, liberal movements have produced in the past.

As we continue to observe pedagogies in action in our quest to positively impact educators and educational settings, let us remember that leaving no stone unturned and no method untried provides the best opportunity for success. Shulman (2005) reminds us:

Professional education is not education for understanding alone; it is preparation for accomplished and responsible practice in the service to others... [professional educators] must come to understand in order to act, and they must act in order to serve. (p. 52)

\section{REFERENCES}

Buss, R. R., Zambo, R., Zambo, D., Perry, J. A., \& Williams, T. R. (2017) Faculty members' responses to implementing re-envisioned EdD programs. Studies in Higher Education, 42(9), 1624-1640. DOI: 10.1080/03075079.2015.1113951.

Golde, C. (2007). Signature pedagogies in doctoral education: are they adaptable for the preparation of education researchers? Educational Researcher, 36(6), 344-351 DOI: 10.3102/0013189X07308301.

Militello, M., Tredway, L., \& Jones, K. D. (2019). A reimagined EdD: Participatory, progressive online pedagogy. In J. Keengwe (Ed.), Handbook of research on blended learning pedagogies and professional development in higher education (pp. 214-243). Hershey, PA: IGI Global.

Olson, K., \& Clark, C. (2009). A signature pedagogy in doctoral education: The leader-scholar community. Educational Researcher, 38(3), 216-221. DOI: $10.3102 / 0013189 \times 09334207$.
Shulman, L. S. (2005). Signature pedagogies in the professions. Daedalus, $134(3), 52-59$ 